\title{
Penentuan Titik-Titik Batas Optimum Strata pada Penarikan Contoh Acak Berlapis dengan Pemograman Dinamik (Kasus : Pengeluaran per Kapita Provinsi Jawa Timur Tahun 2008)
}

\author{
Mahyudi \\ Universitas Muhammadiyah Bengkulu; didimahyudi21@gmail.com \\ Submitted : 15-03-2015, Revised : 30-04-2015, Accepted : 16-06-2015
}

\begin{abstract}
Optimum stratification is the method of choosing the best boundaries that make strata internally homogeneous, given some sample allocation. In order to make the strata internally homogenous, the strata should be constructed in such a way that the strata variances for the characteristic under study be as small as possible. This could be achieved effectively by having the distribution of the main study variable known and create strata by cutting the range of the distribution at suitable points. The problem of finding Optimum Strata Boundaries (OSB) is considered as the problem of determining Optimum Strata Widths (OSW). The problem is formulated as a Mathematical Programming Problem (MPP), which minimizes the variance of the estimated population parameter under Neyman allocation subject to the restriction that sum of the widths of all the strata is equal to the total range of the distribution. The distributions of the study variable are considered as continuous with standard normal density functions. The formulated MPPs, which turn out to be multistage decision problems, can then be solved using dynamic programming technique proposed by Bühler and Deutler (1975). After the counting process using $\mathrm{C}++$ program received the width of each stratum. From these results the optimal boundary point can be determined for each stratum. For the two strata to get the optimal point on the boundary $x_{1}=0.002$. For the formation of three strata obtained the optimal point on the boundary $x_{1}=-0.546$ and $x_{2}=0.552$. For the formation of four strata obtained optimal boundary point is $x_{1}=-0.869, x_{2}=0.003$ and $x_{3}=0.878$. In forming five strata obtained optimal boundary point $x_{1}=-1.096, x_{2}=-0.331, x_{3}=0.339$ and $x_{4}=1.107$. The establishment of a total of six strata obtained the optimal point on the boundary $x_{1}=-1.267$, $x_{2}=-0.569, x_{3}=0.005, x_{4}=0.579$ and $x_{5}=1.281$.
\end{abstract}

Keywords : Stratified Random Sampling, Optimum Stratification, Standard Normal Distribution, Mathematical Programming, Dynamic Programming

\footnotetext{
Abstrak

Stratifikasi optimal adalah cara memilih yang terbaik homogen batas yang membuat strata secara internal, alokasi diberikan sejumlah sampel. Dalam rangka untuk membuat homogen strata secara internal, strata harus dikerjakan secara sedemikian rupa sehingga variansi strata untuk karakteristik dalam kajian menjadi sekecil mungkin. Hal ini dapat dicapai secara efektif dengan memiliki dalam pendistribusian variabel penelitian utama dikenal dan menciptakan strata dengan memotong jangkauan distribusi di cocok poin. Masalah menemukan Optimum Strata Boundaries (OSB) dianggap sebagai masalah menentukan Optimum Strata Widths (OSW). Hal ini yang dirumuskan sebagai
} 
Mathematical Programming Problem (MPP), meminimalkan ruang yang berbeda dari memperkirakan populasi parameter Neyman di bawah alokasi yang tunduk pada pembatasan jumlah yang yang lebar yang sama strata yang berkisar dari distribusi. Penyebaran orang dari variabel baca dianggap sebagai terus menerus dengan kepadatan standar fungsi normal. Yang menyusun MPP, yang ternyata menentukan masalah multistage, kemudian dapat diselesaikan dinamis menggunakan teknik program yang diusulkan oleh Bühler and Deutler (1975). Setelah proses penghitungan menggunakan C++ program menerima lebar dari setiap strata. Dari hasil yang optimal batas bolehkah dilakukan dengan setiap strata. Untuk dua strata untuk mendapatkan optimal titik pada batas $x_{1}=0.002$. Untuk pembentukan tiga strata diperoleh yang optimal titik pada batas $x_{1}=-0.546$ and $x_{2}=0.552$. Untuk pembentukan strata empat diperoleh titik optimal pada batas $x_{1}=-0.869, x_{2}=0.003$ and $x_{3}=0.878$. Batas optimal untuk lima strata $x_{1}=-1.096, x_{2}=-0.331, x_{3}=0.339$ and $x_{4}=1.107$. Pembentukan nilai batas optimaluntuk strata enam yaitu $x_{1}=-1.267, x_{2}=-0.569, x_{3}=0.005, x_{4}=0.579$ and $x_{5}=1.281$.

\section{PENDAHULUAN}

Penarikan contoh (sampling) dalam survei adalah suatu proses untuk memilih sebagian anggota dari suatu populasi dengan prosedur tertentu sehingga dapat digunakan untuk menduga parameter populasi secara sah. Untuk mencapai tujuan tersebut diperlukan metode penarikan contoh yang sesuai. Salah satu teknik penarikan contoh adalah penarikan contoh acak berlapis (stratified random sampling). Pada penarikan contoh acak berlapis, perlu diperhatikan peubah yang digunakan sebagai dasar pembentukan strata. Apabila peubah kualitatif digunakan untuk stratifikasi, pada umumnya pembentukan strata tidak terlalu mengalami masalah, misalnya berdasarkan tingkat pendidikan, pekerjaan dan jenis kelamin. Sebaliknya, jika peubah yang digunakan untuk stratifikasi adalah peubah kuantitatif maka diperlukan teknik tertentu untuk menentukan batas antar strata sesuai dengan kaidah teknik ini.

Pertimbangan dasar yang diperhatikan dalam penentuan batas-batas optimum strata adalah bahwa anggota populasi dalam strata harus sehomogen mungkin dan antar strata seheterogen mungkin, dengan perkataan lain ragam dalam strata harus sekecil mungkin dibandingkan ragam antar strata. Masalah yang timbul adalah penentuan titik optimum batas stratifikasi yang akan membagi populasi menjadi dua atau lebih strata sehingga memenuhi kriteria di atas.

Metode dalam penentuan titik batas optimum strata telah dikemukakan oleh beberapa peneliti. Lavallée dan Hidiroglou (1988) mengusulkan suatu algoritma untuk menentukan batas-batas strata suatu alokasi kuasa untuk contoh yang distrata dari unit-unit contoh yang tidak tentu. Hidiroglou dan Srinath (1993) dalam Khan (2008) menyajikan suatu algoritma yang lebih umum, yaitu dengan memberikan nilai-nilai yang berbeda untuk mengoperasikan parameter-parameter yang menghasilkan alokasi kuasa, alokasi Neyman, atau gabungan dari alokasi-alokasi ini.

Sweet dan Sigman (1995) dalam Khan (2008) dan Rivest (2002) meninjau kembali algoritma Lavallée dan Hidiroglou dan mengusulkan algoritma versi modifikasi yang menggabungkan hubungan berbeda antara stratifikasi dan peubah-peubah yang diteliti. Nicolini (2001) mengusulkan suatu metode yang diberi nama Natural Class Method 
(NCM), untuk menentang metode Dalenius dan Hodges yang paling banyak digunakan, tetapi kedua metode tersebut tidak terbukti lebih efisien dari yang lain.

Lednicki dan Wieczorkowski (2003) dalam Khan (2008) mengajukan metode stratifikasi menggunakan metode simpleks dari Nelder dan Mead (1965) dalam Khan (2008). Kemudian Kozak (2004) menyajikan algoritma pencarian secara acak yang dimodifikasi sebagai metode stratifikasi optimum. Algoritma Kozak benar-benar lebih cepat dan efisien dibandingkan dengan algoritma Rivest, dan Lednicki dan Wieczorkowski dilihat dari kemampuan mengendalikan nilai yang lebih kecil pada fungsi objektif tetapi hal itu tidak dapat menjamin bahwa algoritma tersebut menunjukkan optimum global.

Mengingat bahwa masalah penentuan batas optimum strata ekuivalen dengan masalah menentukan lebar optimum strata Khan et al. (2002) dalam Khan (2008), mengatakan bahwa masalah lebar optimum strata sebagai masalah pemrograman matematika. Khan et al. (2002) menerapkan prosedurnya untuk menentukan batas optimum strata terhadap populasi yang memiliki sebaran uniform dan segitiga siku-siku. Kemudian Khan et al. (2005) memperluas pendekatan pemrograman dinamik untuk menentukan batas optimum strata terhadap peubah eksponensial. Khan et al. (2008) juga melakukan pendekatan pemrograman dinamik terhadap peubah yang memiliki sebaran normal baku.

Salah satu pemrograman matematika yang dapat digunakan dalam menentukan lebar optimum strata adalah pendekatan pemrograman dinamik Bühler dan Deutler (1975). Formulasi masalah pemrograman matematika dengan meminimumkan ragam dari parameter populasi yang diduga berdasarkan alokasi Neyman dengan batasan bahwa jumlah lebar dari semua strata sama dengan total jarak dari sebaran peubah yang diamati.

\section{METODE PENELITIAN}

Data yang digunakan dalam penelitian ini menggunakan data SUSENAS Provinsi Jawa Timur Tahun 2008 berupa data pengeluaran per kapita penduduk sebanyak 8607 Kepala Rumah Tangga. Pembentukan strata dengan menggunakan teknik pemrograman dinamik terbagi menjadi beberapa tahapan sebagai berikut.

Tahap 1. Penyusunan model/ fungsi objektif.

Langkah yang dilakukan pada tahap 1 adalah pembentukan fungsi objektif seperti pada persamaan

$$
\begin{aligned}
& \sum_{h=1}^{L} \operatorname{Sqrt}\left\{\frac { 1 } { 2 \sqrt { 2 \pi } } \left[x_{h-1} \exp \left(-\frac{x_{h-1}^{2}}{2}\right) \operatorname{erf}\left(\frac{y_{h}+x_{h-1}}{\sqrt{2}}\right)-\left(y_{h}+\right.\right.\right. \\
& \left.x_{h-1}\right) \exp \left(-\frac{\left(y_{h}+x_{h-1}\right)^{2}}{2}\right) \operatorname{erf}\left(\frac{y_{h}+x_{h-1}}{\sqrt{2}}\right)-x_{h-1} \exp \left(-\frac{x_{h-1}^{2}}{2}\right) \operatorname{erf}\left(\frac{x_{h-1}}{\sqrt{2}}\right) \\
& \left.+\left(y_{h}+x_{h-1}\right) \exp \left(-\frac{\left(y_{h}+x_{h-1}\right)^{2}}{2}\right) \operatorname{erf}\left(\frac{x_{h-1}}{\sqrt{2}}\right)\right]+\frac{\mathbf{1}}{\mathbf{4}}\left[\operatorname{erf}\left(\frac{y_{h}+x_{h-1}}{\sqrt{2}}\right)-\operatorname{erf}\left(\frac{x_{h-1}}{\sqrt{2}}\right)\right]^{2} \\
& \left.-\frac{1}{2 \pi}\left[\exp \left(-\frac{x_{h-1}^{2}}{2}\right)-\exp \left(-\frac{\left(y_{h}+x_{h-1}\right)^{2}}{2}\right)\right]^{2}\right\} \text { dengan kendala } \sum_{h=1}^{L} y_{h}=d \\
& \quad \text { dan } y_{h} \geq 0 ; h=1,2, \cdots, L
\end{aligned}
$$


dengan fungsi kendala $\sum_{h=1}^{L} y_{h}=d$, dengan $d=x_{L}-x_{0}$. Kemudian tentukan fungsi lebar strata ke- $(h-1)$, yaitu $x_{h-1}$. Substitusikan nilai $x_{h-1}$ ini ke dalam fungsi objektif yang telah disusun. Gunakan prinsip pengoptimalan Bellman, diperoleh hubungan berulang dari teknik pemrograman dinamik sebagai berikut:

$$
\Phi_{k}\left(d_{k}\right)_{0 \leq y_{k} \leq d_{k}}\left[\emptyset_{k}\left(y_{k}\right)+\Phi_{k-1}\left(d_{k}-y_{k}\right)\right], k \geq 2
$$

Untuk langkah pertama, yaitu untuk $k=1: \quad \Phi_{1}\left(d_{1}\right)=\emptyset_{1}\left(d_{1}\right) \Rightarrow y_{1}^{*}=d_{1}$,

(2) dan (3) untuk mendapatkan persamaan rekursifnya.

\section{Tahap 2. Penyelesaian persamaan rekursif.}

Langkah-langkah dalam penyelesaian persamaan rekursif adalah sebagai berikut.

1. Mulai dengan $k=1$. Tetapkan $\Phi\left(0, d_{0}\right)=0$.

2. Hitung $\Phi_{1}\left(d_{1}\right)$, nilai minimum RHS (right hand side) dari persamaan rekursif yang diperoleh untuk $y_{1}=d_{1}, 0 \leq y_{1} \leq d_{1}$ dan $0 \leq d_{1} \leq d$.

3. Simpan nilai $\Phi_{1}\left(d_{1}\right)$ dan $y_{1}$.

4. Untuk $k=2$, nyatakan peubah penjelas sebagai $d_{k-1}=d_{k}-y_{k}$.

5. Tetapkan $\Phi_{k}\left(d_{k}\right)=0$ jika $y_{k}>d_{k}$, di mana $0 \leq d_{k} \leq d$.

6. Hitung $\Phi_{k}\left(d_{k}\right)$, nilai minimum RHS dari persamaan rekursif yang diperoleh untuk $y_{k} ; 0 \leq$ $y_{k} \leq d_{k}$.

7. Simpan nilai $\Phi_{k}\left(d_{k}\right)$ dan $y_{k}$.

8. Untuk $k \geq 3, \cdots, L$, kembali ke langkah 4 .

9. Pada $k=L, \Phi_{L}(d)$ diperoleh sehingga nilai optimum $y_{L}^{*}$ dari $y_{L}$ diperoleh.

10. Pada $k=L-1$, gunakan penghitungan mundur untuk $d_{L-1}=d_{L}-y_{L}$, baca nilai dari $\Phi_{L-1}\left(d_{L-1}\right)$, sehingga nilai optimum $y_{L-1}^{*}$ dari $y_{L-1}$.

11. Ulangi langkah ke-10 sampai nilai optimum $y_{1}^{*}$ dari $y_{1}$ diperoleh dari $\Phi_{1}\left(d_{1}\right)$.

Penyelesaian persamaan rekursif tersebut menggunakan Program $\mathrm{C}++$.

\section{Tahap 3. Penghitungan nilai optimum fungsi objektif.}

Sebagai tahapan terakhir adalah menghitung nilai optimum fungsi objektif untuk setiap strata $L$ yaitu $\sum_{h=1}^{L} \emptyset_{h}\left(y_{h}\right)=\sum_{h=1}^{L} W_{h} \sigma_{h}$.

Untuk mengetahui karakteristik antar strata dilakukan pengujian kehomogenan ragam. Metode statistika untuk menguji kehomogenan ragam adalah uji khi-kuadrat yang dikenal dengan uji Bartlett. Hipotesis yang diuji pada uji Bartlett adalah:

$\mathrm{H}_{0}: \sigma_{1}^{2}=\sigma_{2}^{2}=\cdots=\sigma_{i}^{2}$

$\mathrm{H}_{1}$ : paling sedikit ada satu pasang $\sigma_{i}^{2} \neq \sigma_{i^{\prime}}^{2}$, untuk setiap $i \neq i^{\prime}$, dengan $i=1,2, \cdots, k$

Uji Bartlett dapat dilakukan untuk ulangan sama atau tidak sama. Uji khi-kuadarat untuk jumlah ulangan tidak sama adalah:

$$
\chi_{\text {hitung }}^{2}=\frac{\left(\sum d b_{i}\right)\left(\ln s_{g a b}^{2}\right)-\sum\left(d b_{i} \cdot \ln s_{i}^{2}\right)}{1+\frac{1}{3(k-1)}\left(\sum \frac{1}{d b_{i}}-\frac{1}{\sum d b_{i}}\right)}
$$

dengan $\mathrm{db}$ idalah derajat bebas strata ke-i, $\mathrm{si}^{2}$ adalah ragam dari strata ke-i dan $\mathrm{s}^{2}$ gab adalah ragam gabungan untuk semua strata.

Dengan kaidah keputusan sebagai berikut: 
Apabila $\chi_{\text {hitung }}^{2}>\chi_{\alpha, k-1}^{2}$, maka $\mathrm{H}_{0}$ ditolak artinya kehomogenan ragam tidak dapat dipenuhi. Dan jika sebaliknya hipotesis kehomogenan ragam diterima.

\section{HASIL PENELITIAN DAN PEMBAHASAN}

\section{Data Pengeluaran Per Kapita Propinsi Jawa Timur Tahun 2008}

Jawa Timur adalah provinsi yang terdiri dari 29 kabupaten dan 9 kota. Secara umum wilayah provinsi Jawa Timur dapat dibagi menjadi dua bagian besar yaitu Jawa Timur daratan dan Pulau Madura. Luas wilayah Jawa Timur daratan hampir mencapai 90 persen dari luas keseluruhan, sedangkan wilayah Madura hanya sekitar 10 persen. Data yang digunakan pada penelitian ini adalah data pengeluaran per kapita penduduk Jawa Timur tahun 2008 dengan jumlah contoh $n=8607$ Kepala Rumah Tangga. Data ini diperoleh dari publikas i BPS dari hasil SUSENAS. Dari data tersebut dapat diperoleh informasi bahwa rata-rata pengeluaran per kapita penduduk Jawa Timur adalah Rp337.105,93 dan ragam Rp8.49 x 1010. Pengeluaran minimum adalah sebesar Rp41.349,94 dan pengeluaran maksimum sebesar Rp5.442.241,45.

Setelah dilakukan uji kenormalan Kolmogorov Smirnov terhadap data pengeluaran per kapita tersebut, hasilnya menunjukkan bahwa adanya penyimpangan asumsi tesebut. Karena metode dalam penelitian ini memerlukan asumsi kenormalan, maka data penelitian tersebut harus ditransformasi, dalam hal ini menggunakan transformasi log.

Penentuan Titik-titik Batas Optimum Strata

Untuk data contoh pengeluaran per kapita (nilai setelah diubah menjadi normal standar) dengan $\mathrm{n}=8607$ diperoleh nilai terkecil dan nilai terbesar masing-masing adalah $x_{0}=$ -3.302 dan $x_{L}=5.169$. Ini menunjukkan bahwa jarak dari distribusi adalah

$d=x_{L}-x_{0}=5.169-(-3.302)=8.471$

Sehingga fungsi objektif persamaan (4) dapat dinyatakan sebagai:

Minimumkan

$\sum_{h=1}^{L} \operatorname{Sqrt}\left\{\frac{1}{2 \sqrt{2 \pi}}\left[x_{h-1} \exp \left(-\frac{x_{h-1}^{2}}{2}\right) \operatorname{erf}\left(\frac{y_{h}+x_{h-1}}{\sqrt{2}}\right)-\left(y_{h}+\right.\right.\right.$ $\left.x_{h-1}\right) \exp \left(-\frac{\left(y_{h}+x_{h-1}\right)^{2}}{2}\right) \operatorname{erf}\left(\frac{y_{h}+x_{h-1}}{\sqrt{2}}\right) \quad-x_{h-1} \exp \left(-\frac{x_{h-1}^{2}}{2}\right) \operatorname{erf}\left(\frac{x_{h-1}}{\sqrt{2}}\right)$

$\left.+\left(y_{h}+x_{h-1}\right) \exp \left(-\frac{\left(y_{h}+x_{h-1}\right)^{2}}{2}\right) \operatorname{erf}\left(\frac{x_{h-1}}{\sqrt{2}}\right)\right] \quad+\frac{1}{\mathbf{4}}\left[\operatorname{erf}\left(\frac{y_{h}+x_{h-1}}{\sqrt{2}}\right)-\operatorname{erf}\left(\frac{x_{h-1}}{\sqrt{2}}\right)\right]^{2}$

$\left.-\frac{1}{2 \pi}\left[\exp \left(-\frac{x_{h-1}^{2}}{2}\right)-\exp \left(-\frac{\left(y_{h}+x_{h-1}\right)^{2}}{2}\right)\right]^{2}\right\}$

dengan kendala $\sum_{h=1}^{L} y_{h}=8.471$ dan $y_{h} \geq 0 ; h=1,2, \cdots, L$

Stratifikasi ke- (k-1) diberikan oleh

$$
\begin{aligned}
x_{k-1} & =x_{0}+y_{1}+y_{2}+\cdots+y_{k-1} \\
& =-3.302+y_{1}+y_{2}+\cdots+y_{k-1} \\
& =d_{k-1}-3.302 \\
& =d_{k}-y_{k}-3.302
\end{aligned}
$$

Penyelesaian persamaan rekursif menggunakan pemrograman $\mathrm{C}++$ suntuk menentukan lebar strata optimum $y_{h}$. Tabel 1 menunjukkan hasil dari penyelesaian ini disertai dengan nilai optimum fungsi objektif $\sum_{h=1}^{L} \emptyset_{h}\left(y_{h}\right)=\sum_{h=1}^{L} W_{h} \sigma_{h}$ untuk $L=2,3,4,5$ dan 6 . 
Tabel 1 Titik-titik batas optimum strata dari sebaran normal baku

\begin{tabular}{|c|c|c|c|}
\hline $\begin{array}{c}\text { Jumlah } \\
\text { Strata } \\
\text { L }\end{array}$ & $\begin{array}{l}\text { Lebar Optimum } \\
\text { Strata }\left(y_{h}\right)\end{array}$ & $\begin{array}{l}\text { Titik-titik Batas Optimum } \\
\text { Strata }\left(x_{h}=x_{h-1}+y_{h}\right)\end{array}$ & $\begin{array}{c}\text { Nilai Optimum } \\
\text { Fungsi Objektif } \\
\sum_{h=1}^{L} \emptyset_{h}\left(y_{h}\right)= \\
\sum_{h=1}^{L} W_{h} \sigma_{h}\end{array}$ \\
\hline 2 & $\begin{array}{l}y_{1}=3.303 \\
y_{2}=5.167\end{array}$ & $\begin{array}{cc}\mathrm{x}_{0}=-3.302 & \mathrm{x}_{1}= \\
0.002 & \\
\mathrm{x}_{\mathrm{L}}=5.169 & \end{array}$ & 0.599 \\
\hline 3 & $\begin{array}{l}\mathrm{y}_{1}=2.756 \\
\mathrm{y}_{2}=1.098 \\
\mathrm{y}_{3}=4.617\end{array}$ & $\begin{array}{l}x_{0}=-3.302 \\
x_{1}=-0.546 \\
x_{2}=0.552 \\
x_{L}=5.169\end{array}$ & 0.424 \\
\hline 4 & $\begin{array}{l}y_{1}=2.432 \\
y_{2}=0.873 \\
y_{3}=0.875 \\
y_{4}=4.291\end{array}$ & $\begin{array}{l}x_{0}=-3.302 \\
x_{1}=-0.869 \\
x_{2}=0.003 \\
x_{3}=0.878 \\
x_{L}=5.169\end{array}$ & 0.328 \\
\hline 5 & $\begin{array}{l}y_{1}=2.206 \\
y_{2}=0.765 \\
y_{3}=0.670 \\
y_{4}=0.767 \\
y_{5}=4.062\end{array}$ & $\begin{array}{l}x_{0}=-3.302 \\
x_{1}=-1.096 \\
x_{2}=-0.331 \\
x_{3}=0.339 \\
x_{4}=1.106 \\
x_{L}=5.169\end{array}$ & 0.267 \\
\hline 6 & $\begin{array}{l}y_{1}=2.035 \\
y_{2}=0.698 \\
y_{3}=0.574 \\
y_{4}=0.574 \\
y_{5}=0.702 \\
y_{6}=3.888\end{array}$ & $\begin{array}{l}x_{0}=-3.302 \\
x_{1}=-1.267 \\
x_{2}=-0.569 \\
x_{3}=0.005 \\
x_{4}=0.579 \\
x_{5}=1.280 \\
x_{L}=5.169\end{array}$ & 0.225 \\
\hline
\end{tabular}

\section{Pengujian Kehomogenan Ragam}

Hasil uji khi-kuadrat untuk setiap strata disajikan pada Tabel 2.

Tabel 2 Hasil uji khi-kuadrat untuk setiapjumlah strata

\begin{tabular}{ccccc}
\hline Jumlah Strata L & $\begin{array}{c}\text { Jumlah Contoh } \\
\text { Tiap Strata }\end{array}$ & Ragam Tiap Strata & Nilai $\chi_{\text {hitung }}^{2}$ & P-value \\
\hline $\mathbf{2}$ & $\mathrm{n}_{1}=4755$ & $s_{1}^{2}=0.23$ & 7268.946 & 0.000 \\
& $\mathrm{n}_{2}=3852$ & $s_{2}^{2}=0.58$ & & \\
$\mathbf{3}$ & $\mathrm{n}_{1}=2724$ & $s_{1}^{2}=0.13$ & 13040.803 & 0.000 \\
$\mathrm{n}_{2}=3683$ & $s_{2}^{2}=0.09$ & & \\
$\mathrm{n}_{3}=2200$ & $s_{3}^{2}=0.51$ & &
\end{tabular}




\begin{tabular}{|c|c|c|c|c|}
\hline \multirow[t]{4}{*}{4} & $\mathrm{n}_{1}=1667$ & $s_{1}^{2}=0.10$ & \multirow[t]{4}{*}{17100.023} & \multirow[t]{4}{*}{0.000} \\
\hline & $\mathrm{n}_{2}=3093$ & $s_{2}^{2}=0.06$ & & \\
\hline & $n_{3}=2364$ & $s_{3}^{2}=0.06$ & & \\
\hline & $\mathrm{n}_{4}=1483$ & $s_{4}^{2}=0.48$ & & \\
\hline \multirow[t]{5}{*}{5} & $\mathrm{n}_{1}=983$ & $s_{1}^{2}=0.09$ & \multirow[t]{5}{*}{20157.687} & \multirow[t]{5}{*}{0.000} \\
\hline & $\mathrm{n}_{2}=2534$ & $s_{2}^{2}=0.05$ & & \\
\hline & $\mathrm{n}_{3}=2300$ & $s_{3}^{2}=0.04$ & & \\
\hline & $\mathrm{n}_{4}=1668$ & $s_{4}^{2}=0.05$ & & \\
\hline & $\mathrm{n}_{5}=1122$ & $s_{5}^{2}=0.46$ & & \\
\hline \multirow[t]{6}{*}{6} & $\mathrm{n}_{1}=606$ & $s_{1}^{2}=0.08$ & \multirow[t]{6}{*}{23967.310} & \multirow[t]{6}{*}{0.000} \\
\hline & $\mathrm{n}_{2}=2032$ & $s_{2}^{2}=0.04$ & & \\
\hline & $n_{3}=2126$ & $s_{3}^{2}=0.03$ & & \\
\hline & $\mathrm{n}_{4}=1711$ & $s_{4}^{2}=0.03$ & & \\
\hline & $n_{5}=1224$ & $s_{5}^{2}=0.39$ & & \\
\hline & $\mathrm{n}_{6}=908$ & $s_{6}^{2}=0.44$ & & \\
\hline
\end{tabular}

Dari Tabel 2 terlihat bahwa untuk semua jumlah strata $L$, menghasilkan nilai khikuadrat yang lebih besar daripada nilai khi-kuadrat tabel baik pada taraf nyata $5 \%$ maupun pada taraf nyata $1 \%$. Ini berarti bahwa kehomogenan ragam ditolak, yaitu uji menunjukka $n$ perbedaan yang nyata antara ragam-ragam pada setiap jumlah strata L. Hasil ini juga menunjukkan bahwa ada perbedaan keragaman pada masing-masing strata. Hal ini berarti bahwa antar strata lebih bervariasi karakteristiknya (heterogen).

\section{Pembentukan Strata Pengeluaran Per Kapita Jawa Timur Tahun 2008}

Lebar strata dan titik-titik batas optimum strata pada Tabel 1 merupakan hasil yang didapatkan dari data yang sudah ditransformasi. Untuk data pengeluaran per kapita Propinsi Jawa Timur Tahun 2008 disajikan pada Tabel 3.

Tabel 3 Titik-titik batas optimum strata pengeluaran per kapita Jawa Timur 2008

\begin{tabular}{cccc}
\hline $\begin{array}{c}\text { Jumlah Strata } \\
\mathbf{L}\end{array}$ & $\begin{array}{c}\text { Lebar Optimum } \\
\text { Strata }\left(\boldsymbol{y}_{\boldsymbol{h}}\right)\end{array}$ & $\begin{array}{c}\text { Titik-titik Batas } \\
\text { Optimum Strata }\end{array}$ & Nilai Ragam Strata $\boldsymbol{s}_{\boldsymbol{h}}^{\mathbf{2}}$ \\
\hline $\mathbf{2}$ & $\mathrm{y}_{1}=35933.33$ & $\mathrm{X}_{0}=41349.940$ & $S_{1}^{2}=339422490$ \\
& $\mathrm{Y}_{2}=5164855$. & $\mathrm{x}_{1}=277325.3$ & $S_{2}^{2}=1.281 \mathrm{E}+11$ \\
& & $\mathrm{X}_{\mathrm{L}}=5442241$. & \\
& & $\mathrm{X}_{0}=41349.940$ & $S_{1}^{2}=880588393$ \\
& $\mathrm{y}_{1}=0922.869$ & $\mathrm{x}_{1}=202272.8$ & $S_{2}^{2}=2436769947$ \\
\hline
\end{tabular}




\begin{tabular}{llll}
\hline $\mathrm{y}_{3}=5061394$. & $\mathrm{x}_{2}=380751.9$ & $s_{3}^{2}=1.746 \mathrm{E}+11$ \\
& $\mathrm{x}_{\mathrm{L}}=5442241$. & \\
$\mathrm{y}_{1}=26525.06$ & $\mathrm{x}_{0}=1349.940$ & $s_{1}^{2}=512400483$ \\
$\mathrm{y}_{2}=109712.0$ & $\mathrm{x}_{1}=167875.6$ & $s_{2}^{2}=960333991$ \\
$\mathrm{y}_{3}=181764.5$ & $\mathrm{x}_{2}=277605.1$ & $s_{3}^{2}=2599356842$ \\
$\mathrm{y}_{4}=4982767$. & $\mathrm{x}_{3}=459449.1$ & $s_{4}^{2}=2.159 \mathrm{E}+11$ \\
& & $\mathrm{x}_{\mathrm{L}}=5442241$. & \\
& $\mathrm{y}_{1}=06024.82$ & $\mathrm{x}_{0}=1349.940$ & $s_{1}^{2}=340941512$ \\
$\mathrm{y}_{2}=81428.1$ & $\mathrm{x}_{1}=147398.4$ & $s_{2}^{2}=567979981$ \\
& $\mathrm{y}_{3}=107872.1$ & $\mathrm{x}_{2}=228973.7$ & $s_{3}^{2}=953660359$ \\
& $\mathrm{y}_{4}=187136.5$ & $\mathrm{x}_{3}=336869.8$ & $s_{4}^{2}=2739191510$ \\
$\mathrm{y}_{5}=4918068$. & $\mathrm{x}_{4}=524125.8$ & $s_{5}^{2}=2.492 \mathrm{E}+11$ \\
& & $\mathrm{x}_{\mathrm{L}}=5442241$. & \\
& $\mathrm{y}_{1}=92184.35$ & $\mathrm{x}_{0}=1349.940$ & $s_{1}^{2}=253204999$ \\
$\mathrm{y}_{2}=66063.52$ & $\mathrm{x}_{1}=133543.7$ & $s_{2}^{2}=342296093$ \\
$\mathrm{y}_{3}=78167.16$ & $\mathrm{x}_{2}=199626.4$ & $s_{3}^{2}=472878135$ \\
$\mathrm{y}_{4}=108808.6$ & $\mathrm{x}_{3}=277805.1$ & $s_{4}^{2}=941057357$ \\
$\mathrm{y}_{5}=191543.5$ & $\mathrm{x}_{4}=386780.9$ & $s_{5}^{2}=2840506289$ \\
$\mathrm{y}_{6}=4862690$. & $\mathrm{x}_{5}=579495.9$ & $s_{6}^{2}=2.774 \mathrm{E}+11$ \\
& $\mathrm{x}_{\mathrm{L}}=5442241.452$ & \\
\hline
\end{tabular}

\section{SIMPULAN DAN SARAN}

\section{Simpulan}

Penentuan titik-titik batas optimum strata dapat dianggap sebagai masalah pemrograman matematika dan dapat diselesaikan dengan teknik pemrograman dinamik. Metode ini dapat diterapkan pada data dengan sebaran yang berbeda karena memiliki fungsi objektif yang berbeda pula sesuai dengan sebaran datanya.

Metode ini memberikan hasil berupa lebar masing-masing strata. Oleh karena itu dapat ditentukan titik-titik batas optimum strata dan juga jumlah contoh pada masing-masing strata. Titik-titik batas yang diperoleh menghasilkan ragam di dalam strata sehomogen mungkin dan ragam antar strata seheterogen mungkin.

Untuk dua strata diperoleh titik batas optimum pada $\mathrm{x}_{1}=0.002$. Untuk pembentukan tiga strata diperoleh titik batas optimum pada $x_{1}=-0.546$ dan $x_{2}=0.552$. Untuk pembentukan sebanyak empat strata diperoleh titik batas optimum adalah $\mathrm{x}_{1}=-0.869, \mathrm{x}_{2}=0.003$ dan $\mathrm{x}_{3}=$ 0.878. Pada pembentukan sebanyak lima strata diperoleh titik batas optimum $\mathrm{x}_{1}=-1.096, \mathrm{x}_{2}$ $=-0.331, x_{3}=0.339$ dan $x_{4}=1.107$. Sedangkan untuk pembentukan sebanyak enam strata diperoleh titik batas optimum pada $\mathrm{x}_{1}=-1.267, \mathrm{x}_{2}=-0.569, \mathrm{x}_{3}=0.005, \mathrm{x}_{4}=0.579$ dan $\mathrm{x}_{5}=1.281$.

Metode pemrograman dinamik ini juga memberikan nilai optimum fungsi objektif untuk tiap jumlah strata. Hasilnya menunjukkan bahwa semakin banyak jumlah strata maka nilai optimum fungsi ini akan semakin kecil. Nilai optimum fungsi objektif untuk jumlah stra ta 2, 3, 4, 5, dan 6 berturut-turut adalah 0.599, 0.424, 0.328, 0.267 dan 0.225. 


\section{Saran}

Penentuan strata untuk peubah kuantitatif dengan metode pemrograman dinamik dapat menjadi salah satu alternatif dalam menentukan stratifikasi dalam penelitian survei dan dapat dilakukan untuk data dengan sebaran yang lain selain sebaran normal dengan penentuan sebarannya terlebih dahulu.

\section{DAFTAR PUSTAKA}

Cochran WG. (1977). Sampling Techniques, 3rd Edition. New York: John Willey \& Sons.

Khan EA, Khan MGM, Ahsan MJ. (2002). Optimum Stratification: A Mathematical Programming Approach. Culcutta Statistical Association Bulletin 52 (special):205-208.

Khan MGM, Najmussehar, Ahsan MJ. (2005). Optimum Stratification for Exponential Study Variable Under Neyman Allocation. Journal of Indian Society of Agriculture Statistics 59(2):146-150.

Khan MGM, Niraj Nand, Nesar Ahmad. (2008). Determining The Optimum Strata Boundary Points Using Dynamic Programming. Survey Methodology 34: 205-214.

Kozak M. (2004). Optimal Stratification Using Random Search Method in Agricultural Surveys. Statistics in Transition 6(5):797-806.

Lavallée P. (1988). Two-way Optimal Stratification using Dynamic Programming. Procedings of The Section on Survey Research Methods; Virginia:646-651.

Lavallée P, Hidiroglou M. (1988). On The stratification of Skewed populations. Survey Methodology 14:33-43.

Nicolini G. (2001). A Method to Define Strata Boundaries. Departmental Working Papers 2001-01. Department of Economics, University of Milan, Italy.

Rivest LP. (2002). A Generalization of Lavallée and Hidiroglou Algorithm for Stratification in Business Survey. Survey Methodology 28:191-198. 